\title{
Active surveillance for low-risk prostate cancer
}

\section{Laurence Klotz}

\author{
Address: Department of Surgery, Division of Urology, University of Toronto, Sunnybrook Health Sciences Centre, 2075 Bayview Ave MG 408 , \\ Toronto Ontario M4N3M5 \\ Email: Laurence.klotz@sunnybrook.ca \\ FI000 Medicine Reports 2012, 4:16 (doi:10.3410/M4-16) \\ This is an open-access article distributed under the terms of the Creative Commons Attribution-Non Commercial License \\ (http://creativecommons.org/licenses/by-nc/3.0/legalcode), which permits unrestricted use, distribution, and reproduction in any medium, \\ provided the original work is properly cited. You may not use this work for commercial purposes. \\ The electronic version of this article is the complete one and can be found at: http://f1000.com/reports/m/4/I6
}

\begin{abstract}
Active surveillance for localized prostate cancer entails initial expectant management rather than immediate therapy, with "curative-intent" treatment deferred until there is evidence that the patient is at increased risk for disease progression. This is a response to the clearly documented risks of over diagnosis and overtreatment of low-risk prostate cancer, which in most cases poses little or no threat to the patient. It is based upon the prolonged natural history of prostate cancer and is an attempt to balance the risks and side effects of overtreatment against the possibility of disease progression and a lost opportunity for cure. Low-risk prostate cancer is more accurately viewed as one of multiple risk factors for the presence of higher grade prostate cancer. Like atypical small acinar proliferation, (ASAP), it may be managed with close follow up but without radical intervention, unless there is clear evidence of more aggressive disease.
\end{abstract}

\section{Introduction and background}

Prostate cancer is the commonest internal malignancy in males, and the second commonest cause of cancer death in men [1]. In North America, one in six men (17\%) are now diagnosed with the disease at some point during their life. The life-time risk of dying of the disease is approximately $3 \%$. Thus, approximately 6 times as many men will be diagnosed with the disease as will die from it.

The advent of sensitive diagnostic testing has resulted in the problem of cancer overdiagnosis in multiple organ sites. Welch and Black [2] recently estimated that the "overdiagnosis" rates for prostate, thyroid, and breast cancer (if the entire reservoir of disease were being detected) are 87\%-94\%, 99.7\%-99.9\%, and 43\%-90\% respectively. Those estimates reflect the high prevalence of microfocal disease in the healthy population $(30 \%-$ $70 \%$ for prostate, $36 \%-100 \%$ for thyroid, and $7 \%-39 \%$ for breast cancer).

Because of the high incidence of latent prostate cancer in aging men, the widespread availability of the prostatespecific antigen (PSA) test, and the long term effects of definitive therapy, this has the greatest ramifications in the case of prostate cancer.

\section{Screening and overdiagnosis}

Screening for prostate cancer with PSA is widely used in North America and Europe. Compared with clinical diagnosis, it results in the identification of potentially lethal prostate cancer at a much more curable stage. The widespread use of PSA screening has been associated with significant falls in prostate cancer mortality [2]. There is some controversy, however, as to the degree to which PSA-based early detection has been responsible for this reduction. A credible estimate is that $50 \%$ of the mortality reduction is related to PSA screening [3]. On the other hand, the cost is a very high rate of diagnosis and treatment - of prostate cancer.

The recently published European Randomized Trial of Screening for Prostate Cancer (ERSPC) reported that in 180,000 men randomized either to PSA screening every 4 years or to usual care prostate cancer mortality was reduced by $20 \%$ [4]. The "number needed to treat" for each prostate cancer death avoided in ERSPC was 48 
(i.e. each cancer death avoided required treating an extra 48 patients). It is widely anticipated that this number needed to treat figure will fall with longer follow up. A more recent randomized screening study from Goteborg [5], which had considerably longer median follow up (14 years) than the other screening studies, estimated the mortality reduction with screening at $50 \%$, and, indeed, the number needed to treat was 12 . Further, a sub-analysis of the negative PLCO study showed that in men with little or no co-morbidity, the number needed to treat was 5 at 10 years [6]. However, most patients dying of prostate cancer had intermediate- or high-grade disease. The number needed to treat with low-grade, small-volume prostate cancer for each death avoided is likely to be considerably higher.

Recently, the US Preventive Services Task Force published new recommendations on the use of PSA for screening, assigning it to level ' $\mathrm{D}$ ', i.e. the risks outweigh the benefit [7]. The primary reason for this was due to concerns about overdiagnosis and overtreatment. The problem with accepting the Task Force recommendation, and discarding PSA testing altogether, is that this will result in a return to the pre-PSA era of men with prostate cancer presenting with advanced, incurable disease. We believe, based on one large randomized trial, as well as inferences from many other studies, that treatment of some prostate cancers saves lives and reduces mortality from the disease [8].

An alternative strategy, which potentially offers the best of both worlds, is based on the idea that treatment must be applied selectively, and the timing and aggressiveness of treatment should reflect disease and patient characteristics.

The likelihood of 'true' microfocal low-grade disease progressing to metastatic disease appears to be extremely low. Historically, of course, a few patients with apparent low-risk prostate cancer develop metastatic disease and die of prostate cancer. Recent evidence indicates that these patients were almost certainly under-graded at the original biopsy, and in fact, harbored higher-grade cancer from the start [9]. Thus, the challenge of selective therapy is the early identification of the patients with higher-grade cancer than seen diagnosed on the basis of the original biopsy.

\section{Definition of clinically insignificant prostate cancer}

Low-risk prostate cancer has been defined by D'Amico as Gleason score of 6 or less, PSA less than $10 \mathrm{mg} / \mathrm{ml}$, and a tumor that is either non-palpable or only palpable in less than half of one lobe of the prostate (clinical stage T1c or T2a) [10]. Very low-risk disease has been defined by
Epstein as low-risk patients who have only one or two positive cores, no more than $50 \%$ involvement of any one core, and a PSA density of $<0.15$ [11]. This definition is based on data demonstrating that these patients have a very high likelihood of "clinically insignificant" prostate cancer. A key concept is the pathologic definition of clinically insignificant prostate cancer. For 30 years, this has been defined as Gleason score of 6 or less, prostate cancer with a prostate tumor volume $<0.5 \mathrm{cc}$, based on work by T. Stamey on cystoprostatectomy specimens [12]. There is much evidence that this is an overly stringent definition. Recently, the ERSPC group performed a similar analysis based on the ERSPC patients [13]. Their conclusion was that the threshold for clinically insignificant disease was a cancer volume $<1.3 \mathrm{cc}$. This has major implications. It means that a better test for prostate cancer would ignore small volume disease, and identify cancers of 1.3 cc or greater.

\section{Active surveillance results}

Active surveillance means deferring treatment initially for a growing proportion of men diagnosed with low-risk (i.e. low volume, stage and grade) prostate cancer. Men are followed carefully with serial PSA assessments, repeat biopsies, and in some cases other tests intended to identify early signs of progression (such as MRI and biomarkers). The term "active surveillance" has supplanted "watchful waiting," but the two are not synonymous. The latter term is generally applied to older men with significant comorbidity, who were advised to defer treatment unless symptoms of advanced disease developed, at which point palliative androgen deprivation could be offered. Active surveillance, on the other hand, rests on the presumptions that the lead time from diagnosis to clinical progression is usually long for lowrisk disease [9], and that at the first signs of higher-risk disease the cancer can be treated, within the window of opportunity for cure. The distinction is particularly important in that neither oncologic, nor quality of life, outcomes from patients assigned to observation in older randomized trials, $[8,14]$, nor those identified in population-based registries as receiving conservative management, can be considered representative of those expected with contemporary active surveillance.

Table 1 summarizes the published prospective experience with active surveillance, comprising more than 2900 patients [15-23]. These studies differ in terms of their eligibility and triggers for intervention. However, certain consistent themes emerge from these data.

Over time, approximately one third of patients will be reclassified as higher risk for progression and will be offered treatment. This proportion depends on how 
Table I. Outcomes of active surveillance in large prospective series

\begin{tabular}{|c|c|c|c|c|c|c|}
\hline $\begin{array}{l}\text { Author, } \\
\text { location }\end{array}$ & $\begin{array}{r}\text { Year } \\
\text { published }\end{array}$ & Patients & $\begin{array}{r}\text { Median } \\
\text { follow-up } \\
\text { (month) }\end{array}$ & $\begin{array}{r}\% \text { treated; } \\
\text { treatment free } \%\end{array}$ & $\begin{array}{r}\text { Overall/Disease } \\
\text { specific } \\
\text { survival (\%) }\end{array}$ & $\begin{array}{r}\% \text { BCR post } \\
\text { deferred treatment }\end{array}$ \\
\hline Klotz et al. [15] & 2009 & 450 & 80 & $30 ; 72$ at $5 y r$ & $79 / 97$ at $10 y r$ & $50 \%$ (I3\% overall) \\
\hline University of Toronto, Canada & & & & & & \\
\hline $\begin{array}{r}\text { Van den Bergh et al. [16], } \\
\text { Multicentre, Europe }\end{array}$ & 2009 & 616 & 47 & $32 ; 43$ at $10 y r$ & $77 / 100$ at $10 y r$ & $20 \% \wedge$ \\
\hline $\begin{array}{r}\text { Dall'Era et al. [17] University } \\
\text { of California } \\
\text { San Francisco (UCSF), USA }\end{array}$ & 2008 & 328 & 43 & $24 ; 67$ at $5 y r$ & $100 / 100$ at $5 y r$ & NR \\
\hline $\begin{array}{l}\text { Kakehi et al. [18], } \\
\text { Multicentre, Japan }\end{array}$ & 2008 & 118 & 36 & $51 ; 49$ at $3 y r$ & NR & NR \\
\hline $\begin{array}{l}\text { Carter et al. [19], } \\
\text { Johns Hopkins, USA }\end{array}$ & 2007 & 407 & NR & 36; NR & NR & $\begin{array}{r}\text { NR [50\% "incurable" based on } \\
\text { pathology post surgery] }\end{array}$ \\
\hline $\begin{array}{l}\text { Roemeling et al. [20], } \\
\text { Rotterdam Netherlands }\end{array}$ & 2007 & 273 & 41 & $29 ; 71$ at $5 y r$ & $89 / 100$ at $5 y r$ & NR [3I\% of I 3 RP positive margins] \\
\hline Soloway et al. [2I], Miami, USA & 2007 & 99 & 35 & $8 ; 85$ at $5 y r$ & NR & NR \\
\hline $\begin{array}{l}\text { Hardie et al. [22], } \\
\text { Royal Marsden, UK }\end{array}$ & 2005 & 80 & 42 & $14 ; 79$ at $5 y r$ & NR & $0 \%$ \\
\hline $\begin{array}{r}\text { Patel et al. [23], } \\
\text { Memorial Sloan Kettering, USA }\end{array}$ & 2004 & 88 & 35 & $35 ; 58$ at $5 y r$ & NR & NR \\
\hline
\end{tabular}

stringently patients are evaluated at baseline, how "liberal" the inclusion criteria for surveillance are, and how quick the clinician is to pull the trigger for treatment. A very stringent approach restricting surveillance to men who have had extended biopsies with only one or two positive cores with minimal disease on those cores will likely identify a cohort more likely to remain untreated. This will also mean that many men with indolent disease will not be offered surveillance.

In most cases that are reclassified as higher risk, the reclassification is due to upgrading at the time of repeat biopsy. This upgrading is not time dependent, suggesting strongly that it is due to more accurate sampling rather than true biologic progression [9]. After an initial extended biopsy (10-14 cores), approximately $25 \%$ of patients will be found to have higher grade cancer on repeat biopsy. More than $90 \%$ of these have Gleason scores of $3+4$. This emphasizes the critical importance of a confirmatory biopsy performed within a reasonable time period (i.e. within one year) of the initial diagnosis.

In the intermediate time-frame (5-15 years), prostate cancer mortality is exceptionally low. In the collected series, approximately 300 patients have been followed for between 10 and 15 years. To date, none of the prostate cancer deaths in men on surveillance have occurred after the 10-year time point. Among the 453 patients in the Toronto cohort, the actuarial 10-year prostate cancer survival is $97 \%$ [15].

In most men on prostate cancer surveillance, mortality comes from other causes. In the most mature cohort (Toronto), with a median follow up of 8 years, the relative risk for non-prostate-cancer death was 19 times that for prostate cancer mortality. Although prostate cancer mortality is likely to increase as the surveillance cohorts mature, so will non-prostate-cancer mortality.

In the Toronto cohort, only PSA doubling time was a predictor for prostate cancer mortality. The doubling time amongst the five patients who died of disease was 1.6 years or less, falling within the lowest $10^{\text {th }}$ percentile of PSA doubling times for the cohort. All patients who died were found to have a Gleason score of 7 or greater disease on repeat biopsy [24].

The relative risk of prostate cancer in comparison with other-cause mortality is directly correlated with the age of the patient at diagnosis - insofar as the risk of other-cause mortality is a function of age. In men under 70 years of age, the cumulative hazard ratio for non-prostate to prostate cancer death was 9:1.

The limitation of these studies is the length of follow-up, as it will require another 5-7 years before the most mature of these studies will have a median 15 years of follow-up. Nonetheless, the results to date are extremely encouraging.

\section{Biopsy}

All patients contemplating surveillance must have a confirmatory biopsy within 12 months of the original biopsy. This biopsy should specifically target the anterior prostate and antero-lateral horn, as well as the traditional posterior peripheral zone.

If the confirmatory biopsy is negative or shows microfocal Gleason score of 6 , subsequent biopsies should be performed every 3-4 years, depending on PSA kinetics 
and/or clinical examination of the prostate. At age 80, biopsies may be discontinued (due to diminishing benefit of treatment of early prostate cancer) unless there are striking changes in PSA or prostate examination.

\section{PSA testing}

PSA testing should be performed every three months for two years, and then every six months indefinitely. PSA doubling time or velocity should be calculated based, preferably, on 8-9 data points over a two year period. A PSA doubling time of $>3$ years is considered "stable", and such patients should be managed with ongoing surveillance unless there is a change in Gleason grade on biopsy.

\section{Triggers for intervention}

In several of the published series, PSA doubling time or velocity has been used as a trigger for definitive intervention. A short doubling time and/or a PSA velocity $>2.0 \mathrm{ng} / \mathrm{ml} /$ year is associated with a worse prognosis in many prostate cancer states. In men with an intact androgen axis, progression to metastatic disease is almost always accompanied by a substantial increase in PSA. In the Toronto cohort, $100 \%$ of patients who have progressed to metastatic disease have had a PSA doubling time $<2$ years. However, some recent studies have questioned the correlation between PSA kinetics and adverse disease characteristics [25]. A recent overview of this subject concluded that PSA kinetics, although predictive, did not add predictive value to absolute PSA, and should not be used for decision making in localized prostate cancer [26]. Our own experience was that, in the stable, untreated patients in our cohort a "false PSA trigger" for intervention occurred in up to 50\% [27]. Thus, our current approach is to use PSA kinetics as a guide for further evaluation, rather than a trigger for intervention on its own.

A common dilemma in managing surveillance patients occurs when the biopsy shows only a minimal Gleason score of 6 , but the PSA is rising rapidly. Multiparametric MRI represents a way out of this dilemma. A "normal" MRI has been reported to have a negative predictive value of $94-97 \%$ for high-grade cancer, based on a single centre experience [28]. This figure must be validated. Nonetheless, this makes multiparametric MRI extremely useful in this setting [29]. The finding of a "significant" lesion on MRI in a patient on active surveillance should trigger either a targeted biopsy or definitive intervention. An equivocal lesion should trigger a repeat biopsy of the lesion.

\section{Role of 5-alpha reductase inhibitors}

In the Prostate Cancer Prevention Trial (РСPT), the likelihood of low-grade prostate cancer being found on a biopsy was reduced by $25 \%$ by finasteride $[4,30]$. A similar finding was observed in the REDUCE trial [31]. An obvious inference is that 5 -alpha reductase inhibitors may be beneficial in men on surveillance. This was evaluated in a prospective randomized trial [32]; men on surveillance were randomized between dutasteride and placebo for 3 years, and had a mandated biopsy at 18 months and 3 years. At 3 years, 54 (38\%) of 144 men in the dutasteride group and 70 (48\%) of 145 controls had prostate cancer progression (pathological or therapeutic; hazard ratio 0.62, p = 0.009): $35(24 \%)$ men in the dutasteride group and $23(15 \%)$ controls had sexual adverse events or breast enlargement or tenderness. There was no increase in high-grade cancer (although the study was not powered to find a $0.5 \%-1 \%$ increase, seen in the PCPT and REDUCE trials). The study suggests that there may be a benefit of 5-alpha reductase inhibitors in reducing the rate of progression in men on surveillance.

\section{Quality of life}

Several studies have addressed quality of life issues in men managed conservatively. Compelling data come from the comparison of men in the Scandinavian randomized trial comparing radical prostatectomy to watchful waiting [33]. This showed no difference in any psychological domain between the surgery and watchful waiting group, but distress was more common in the former. A recent Finnish quality of life study in 126 men on surveillance found that this approach did not provoke short-term quality-of-life disturbances, as assessed by standardized RAND-36, IIEF-5 and IPSS questionnaires [34]. None of the patients changed treatment due to anxiety. Unexpectedly, prostate cancer patients on active surveillance had significantly better general mental and physical health-related quality of life than did a sample of the general age-stratified Finnish male population. Another US study reported improved quality of life in 125 men on surveillance compared to men treated shortly after diagnosis [35]. The published literature supports improved quality of life in men managed conservatively, with no apparent adverse psychological effect of living with untreated cancer.

\section{Future studies}

The PROTECT trial, a trial of newly diagnosed prostate cancer patients carried out in the UK, has randomized 900 men between surgery, radiation, and 'watchful waiting'. The patients on the latter arm were offered intervention if re-classified as higher risk over time, although this was not formally built into the protocol. This trial should provide invaluable information about the relative mortality associated with these treatment approaches. 
The next five years will also see the publication of more mature prospective surveillance trials, including the outcome of patients followed conservatively for 15 years or more. Other areas of very active research include the role of multiparametric MRI and new biomarkers in patient selection and decision making. Further data on long term quality of life effects are also anticipated.

\section{Summary and conclusion}

For men with low-grade prostate cancer who place a high premium on avoiding the side effects of definitive treatment, and who accept the slight increased risk of late metastasis or death, active surveillance is an appealing strategy. The optimal criteria include clinical stage T1c or T2a, serum PSA $<10 \mathrm{mg} / \mathrm{ml}$, and a Gleason score of 6 or less. This represents about $45 \%$ of newly diagnosed patients in the US and Canada, approximately 150,000 men per year.

An important corollary is that young patients who have microfocal disease only can be managed with an initial surveillance approach. The quality of life benefits of maintaining normal erectile and voiding function are enhanced in young men. The risk of progression of lowgrade disease is low.

A repeat prostate biopsy should be performed at one year, to rule out higher-grade disease that may have been missed on the original biopsy. Following this, biopsies should be repeated every three to four years (until age 80) to look for evidence of biologic progression to a Gleason score of $4+3$ or higher.

Active surveillance is becoming widely accepted. A recent National Institutes of Health "State of the Science" report concluded that "an independent panel" convened by the NIH has concluded that many men with localized, lowrisk prostate cancer should be closely monitored, permitting treatment to be delayed until warranted by disease progression [36].

This approach is associated with an extremely small risk of prostate cancer mortality, currently estimated at 3\% at 10 years. Recognizing that not all prostate cancer deaths are preventable, even with aggressive treatment of all patients, it is likely that the number of patients who will succumb "unnecessarily" is smaller, likely one in several hundred. Further, these "preventable" deaths occur many years after diagnosis, in many cases close to the end of the patient's natural life. Compared to the morbidity associated with treating all such patients radically, this is a small price to pay and makes active surveillance an easy choice for well-informed patients.

\section{Abbreviations}

PSA, prostate-specific antigen; ERSPC, European Randomized Trial of Screening for Prostate Cancer; PCPT, Prostate Cancer Prevention Trial; MRI, magnetic resonance imaging.

\section{Competing interest}

The author declares that he has no competing interests.

\section{References}

I. Jemal A, Siegel R, Xu J, Ward E: Cancer statistics, 20 I 0. CA Cancer J Clin 2010, 60:277-300.

FI000 Factor 6

Laurence Klotz 23 Jul 2012

2. Welch HG, Black WC: Overdiagnosis in cancer. J Natl Cancer Inst 2010, 102:605-13.

FI000 Factor 9

Iris Zalaudek and Aimilios Lallas 22 Sep 20I I, Laurence Klotz 23 Jul 2012

3. Wever EM, Draisma G, Heijnsdijk EAM, de Koning HJ: How does early detection by screening affect disease progression? Modeling estimated benefits in prostate cancer screening. Med Decis Making 20I I, 3 I:550-8.

FI000 Factor 6

Laurence Klotz 23 Jul 2012

4. Schröder FH, Hugosson J, Roobol MJ, Tammela TLJ, Ciatto S, Nelen V, Kwiatkowski M, Lujan M, Lilja H, Zappa M, Denis LJ, Recker F, Berenguer A, Määttänen L, Bangma CH, Aus G, Villers A, Rebillard X, van der Kwast T, Blijenberg BG, Moss SM, de Koning HJ, Auvinen A: Screening and prostate-cancer mortality in a randomized European study. N Engl J Med 2009, 360:1320-8.

FI000 Factor 15

Karl-Dietrich Sievert 17 Apr 2009, Andreas Skolarikos and Grigoris Athanasiadis 0I May 2009, Cornelis Biesheuvel 07 May 2009, William Dale and Saleha Sajid 24 Feb 2010, Laurence Klotz 23 Jul 2012

5. Hugosson J, Carlsson S, Aus G, Bergdahl S, Khatami A, Lodding P, Pihl C, Stranne J, Holmberg E, Lilja H: Mortality results from the Göteborg randomised population-based prostate-cancer screening trial. Lancet Oncol 2010, I I:725-32.

\section{FI000 Factor II}

James Catto and Kate Linton 06 Jul 2010, Guido Barbagli and Massimo Lazzeri 09 Nov 2010, Laurence Klotz 23 Jul 2012

6. Crawford ED, Grubb R, Black A, Andriole GL, Chen M, Izmirlian G, Berg CD, D'Amico AV: Comorbidity and mortality results from a randomized prostate cancer screening trial. J Clin Oncol 2011 , 29:355-61.

FI000 Factor 9

James Catto and Kate Linton 17 Feb 20II, Laurence Klotz 23 Jul 2012

7. Screening for Prostate Cancer: A Review of the Evidence for the U.S. Preventive Services Task Force [http://www.uspreventiveservicestaskforce.org/uspstfI 2/prostate/prostateart.htm]

8. Bill-Axelson A, Holmberg L, Ruutu M, Garmo H, Stark JR, Busch C, Nordling S, Häggman $M$, Andersson S, Bratell S, Spångberg A, Palmgren J, Steineck G, Adami H, Johansson J: Radical prostatectomy versus watchful waiting in early prostate cancer. $N$ Engl J Med 20II, 364:1708-17.

FI000 Factor 14

Thomas Flaig 24 May 20I I, Hendrik van Poppel and Yuri Tolkach 26 Apr 2012, Laurence Klotz 23 Jul 2012 
9. Porten SP, Whitson JM, Cowan JE, Cooperberg MR, Shinohara K, Perez N, Greene KL, Meng MV, Carroll PR: Changes in prostate cancer grade on serial biopsy in men undergoing active surveillance. J Clin Oncol 20I I, 29:2795-800.

FI000 Factor 6

Laurence Klotz 23 Jul 2012

10. D'Amico AV, Whittington R, Malkowicz SB, Schultz D, Schnall M, Tomaszewski JE, Wein A: A multivariate analysis of clinical and pathological factors that predict for prostate specific antigen failure after radical prostatectomy for prostate cancer. J Urol 1995, 154:|3|-8.

FI000 Factor 6

Laurence Klotz 23 Jul 2012

II. Epstein JI: Prognostic significance of tumor volume in radical prostatectomy and needle biopsy specimens. J Urol 2011, 186:790-7.

FI000 Factor 6

Laurence Klotz 23 Jul 2012

12. Stamey TA, Freiha FS, McNeal JE, Redwine EA, Whittemore AS, Schmid HP: Localized prostate cancer. Relationship of tumor volume to clinical significance for treatment of prostate cancer. Cancer 1993, 71:933-8.

FI000 Factor 6

Laurence Klotz 23 Jul 2012

13. Wolters T, Roobol MJ, van Leeuwen PJ, van den Bergh RCN, Hoedemaeker RF, van Leenders GJLH, Schröder FH, van der Kwast TH: A critical analysis of the tumor volume threshold for clinically insignificant prostate cancer using a data set of a randomized screening trial. J Urol 20II, I85:121-5.

FI000 Factor 6

Laurence Klotz 23 Jul 2012

14. Klotz L, Thompson I: Early prostate cancer-treat or watch? $N$ Engl J Med 20I I, 365:569.

15. Klotz L, Zhang L, Lam A, Nam R, Mamedov A, Loblaw A: Clinical results of long-term follow-up of a large, active surveillance cohort with localized prostate cancer. J Clin Oncol 2010, 28:|26-3|.

16. van den Bergh RCN, Roemeling S, Roobol MJ, Aus G, Hugosson J, Rannikko AS, Tammela TL, Bangma CH, Schröder FH: Outcomes of men with screen-detected prostate cancer eligible for active surveillance who were managed expectantly. Eur Urol 2009, 55:I-8.

\section{FI000 Factor 6}

Laurence Klotz 23 Jul 2012

17. Dall'Era MA, Konety BR, Cowan JE, Shinohara K, Stauf F, Cooperberg MR, Meng MV, Kane C], Perez N, Master VA, Carroll PR: Active surveillance for the management of prostate cancer in a contemporary cohort. Cancer 2008, I I 2:2664-70.

18. Kakehi $Y$, Kamoto T, Shiraishi T, Ogawa O, Suzukamo Y, Fukuhara S, Saito Y, Tobisu K, Kakizoe T, Shibata T, Fukuda H, Akakura K, Suzuki H, Shinohara N, Egawa S, Irie A, Sato T, Maeda O, Meguro N, Sumiyoshi Y, Suzuki T, Shimizu N, Arai Y, Terai A, Kato T, Habuchi T, Fujimoto H, Niwakawa M: Prospective evaluation of selection criteria for active surveillance in Japanese patients with stage TI cN0M0 prostate cancer. Jpn J Clin Oncol 2008, 38:122-8.

19. Carter HB, Kettermann A, Warlick C, Metter EJ, Landis P, Walsh PC, Epstein Jl: Expectant management of prostate cancer with curative intent: an update of the Johns Hopkins experience. J Urol 2007, 178:2359-64; discussion; 2364-5.

FI000 Factor 6

Laurence Klotz 23 Jul 2012

20. Roemeling S, Roobol MJ, de Vries SH, Wolters T, Gosselaar C, van Leenders GJLH, Schröder FH: Active surveillance for prostate cancers detected in three subsequent rounds of a screening trial: characteristics, PSA doubling times, and outcome. Eur Urol 2007, 5 I: 1244-50; discussion I25I.

FI000 Factor 6

Laurence Klotz 23 Jul 2012

21. Soloway MS, Soloway CT, Eldefrawy A, Acosta K, Kava B, Manoharan M: Careful selection and close monitoring of lowrisk prostate cancer patients on active surveillance minimizes the need for treatment. Eur Urol 2010, 58:83I-5.

FI000 Factor 9

Alexander Bachmann and Matthias Walter 0I Mar 20II, Laurence Klotz 23 Jul 2012

22. Hardie C, Parker C, Norman A, Eeles R, Horwich A, Huddart R, Dearnaley D: Early outcomes of active surveillance for localized prostate cancer. BJU Int 2005, 95:956-60.

23. Patel MI, DeConcini DT, Lopez-Corona E, Ohori M, Wheeler T, Scardino PT: An analysis of men with clinically localized prostate cancer who deferred definitive therapy. J Urol 2004, 171:1520-4.

24. Krakowsky Y, Loblaw A, Klotz L: Prostate cancer death of men treated with initial active surveillance: clinical and biochemical characteristics. J Urol 2010, 184:131-5.

25. Ross AE, Loeb S, Landis P, Partin AW, Epstein Jl, Kettermann A, Feng Z, Carter HB, Walsh PC: Prostate-specific antigen kinetics during follow-up are an unreliable trigger for intervention in a prostate cancer surveillance program. J Clin Oncol 2010, 28:2810-6.

FI000 Factor 8

Robert Huddart 01 Jul 2010, Michael Glode and Thomas Flaig I 3 Jul 2010, Laurence Klotz 23 Jul 2012

26. Vickers AJ, Savage C, O'Brien MF, Lilja H: Systematic review of pretreatment prostate-specific antigen velocity and doubling time as predictors for prostate cancer. J Clin Oncol 2009, 27:398-403.

FI000 Factor 9

George Thalmann 18 Jun 2009, Laurence Klotz 23 Jul 2012

27. Loblaw A, Zhang L, Lam A, Nam R, Mamedov A, Vesprini D, Klotz L: Comparing prostate specific antigen triggers for intervention in men with stable prostate cancer on active surveillance. J Urol 2010, 184:1942-6.

28. Villeirs GM, de Meerleer GO, de Visschere PJ, Fonteyne VH, Verbaeys AC, Oosterlinck W: Combined magnetic resonance imaging and spectroscopy in the assessment of high grade prostate carcinoma in patients with elevated PSA: a singleinstitution experience of 356 patients. Eur J Radiol 20II, 77:340-5.

29. Delongchamps NB, Beuvon F, Eiss D, Flam T, Muradyan N, Zerbib M, Peyromaure M, Cornud F: Multiparametric MRI is helpful to predict tumor focality, stage, and size in patients diagnosed with unilateral low-risk prostate cancer. Prostate Cancer Prostatic Dis 20II, 14:232-7.

\section{FI000 Factor 6}

Laurence Klotz 23 Jul 2012

30. Thompson IM, Goodman PJ, Tangen CM, Lucia MS, Miller GJ, Ford LG, Lieber MM, Cespedes RD, Atkins JN, Lippman SM, Carlin SM, Ryan A, Szczepanek CM, Crowley JJ, Coltman CA: The influence of finasteride on the development of prostate cancer. N Engl J Med 2003, 349:2 I5-24.

FI000 Factor 6

Laurence Klotz 23 Jul 2012

31. Andriole GL, Bostwick DG, Brawley OW, Gomella LG, Marberger M, Montorsi F, Pettaway CA, Tammela TL, Teloken C, Tindall DJ, Somerville MC, Wilson TH, Fowler IL, Rittmaster RS: Effect of 
dutasteride on the risk of prostate cancer. N Engl J Med 20I0, 362: 1192-202.

FI000 Factor 15

John Amory 12 Apr 2010, James Catto and Kate Linton 26 Apr 2010, Benjamin Davies and Jeffrey Tomaszewski 27 Apr 2010 Jaspreet Sandhu 25 May 2010, Jean Pierre Droz and Helen Boyle 25 Jun 2010, Laurence Klotz 23 Jul 2012

32. Fleshner NE, Lucia MS, Egerdie B, Aaron L, Eure G, Nandy I, Black L, Rittmaster RS: Dutasteride in localised prostate cancer management: the REDEEM randomised, double-blind, placebocontrolled trial. Lancet 2012, 379: I I03-II.

FI000 Factor 19

James Catto and Kate Linton 20 Feb 2012, Thomas Flaig 22 Feb 2012, Robert Huddart 16 Mar 2012, Yoshihiko Hirao and Kiyohide Fujimoto 29 Mar 2012, Hendrik van Poppel and Yuri Tolkach 05 Jul 2012, Laurence Klotz 23 Jul 2012

33. Johansson E, Steineck G, Holmberg L, Johansson J, Nyberg T, Ruutu M, Bill-Axelson $A$ : Long-term quality-of-life outcomes after radical prostatectomy or watchful waiting: the Scandinavian Prostate Cancer Group-4 randomised trial. Lancet Oncol 201 I, I 2:89I-9.

FI000 Factor 9

James Catto and Kate Linton 26 Sep 20II, Laurence Klotz 23 Jul 2012

34. Vasarainen H, Lokman U, Ruutu M, Taari K, Rannikko A: Prostate cancer active surveillance and health-related quality of life: results of the Finnish arm of the prospective trial. BJU Int 20I2, 109:1614-9.

FI000 Factor 6

Laurence Klotz 23 Jul 2012

35. Kasperzyk JL, Shappley WV, Kenfield SA, Mucci LA, Kurth T, Ma J, Stampfer MJ, Sanda MG: Watchful waiting and quality of life among prostate cancer survivors in the Physicians' Health Study. J Urol 20II, I86:1862-7.

36. NIH State-of-the-Science Conference: Role of Active Surveillance in the Management of Men With Localized Prostate Cancer [http:// consensus.nih.gov/201 I/prostate.htm] 